\title{
Clinical Efficacy of Medicinal Leech Therapy in Treating Third- and Fourth-Degree Hemorrhoids
}

\section{Eficácia clínica da hirudoterapia no tratamento de hemorroidas de terceiro e quarto graus}

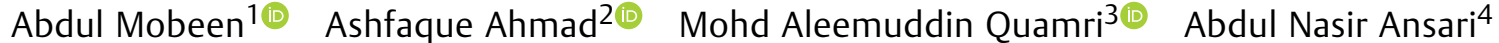

1 Department of Moalajat (Medicine), National Institute of Unani Medicine, Bangalore, India

2 Department of Moalajat, Saifia Hamidia Unani Tibbiya College, Burhanpur, MP, India

${ }^{3}$ Department of Moalajat (Medicine), National Institute of Unani Medicine, Bangalore, India

${ }^{4}$ Department of Ilaj Bit Tadbeer, National Institute of Unani Medicine, Bangalore, India

J Coloproctol 2021;41(2):124-130.
Address for correspondence Abdul Mobeen, MD, Unani Medicine, National Institute of Unani Medicine, Bengaluru, India (e-mail: me8nium@gmail.com).

\begin{abstract}
Objectives Hemorrhoids are characterized by bleeding, mucous discharge, itching, pain, and prolapse. This condition is known as bawaseer in Unani medicine, and Hirudinaria granulosa has been used for its treatment in Irsal-e Alaq, or medicinal leech therapy (MLT), for centuries. Hirudinaria granulosa with antithrombotic and antiinflammatory action is used in the treatment of chronic venous disease and hemorrhoids. The present study was aimed to investigate the efficacy of MLT in third and fourth-degree hemorrhoids.

Methods A single-centre prospective, clinical trial with a pre and postanalysis design was conducted at the hospital of the National Institute of Unani Medicine. Twenty male and female patients, with a mean age of 38 years, presenting moderate symptoms assessed with the colorectal evaluation of clinical therapeutics scale (CORECTS) questionnaire were included in the study. Hirudinaria granulosa were applied around the pile mass for 15 minutes weekly, for 4 weeks. The efficacy of the treatment was measured by an objective and subjective assessment using the CORECTS.

Results When analyzed by the clinician, MLT reduced the symptoms' severity score in

\section{Keywords}

- hemorrhoids

- medicinal leach therapy

- Unani medicine

- bawaseer

- irsal-e-alaq the following domains: pain (55\% improvement; $p<0.001$ ); anorectal itching (30\% improvement; $p<0.10)$; and bleeding (10\% improvement; $p<0.7963)$. Significant improvement $(p<0.001)$ was reported in the CORECTS score in relation to pain (44.09\% improvement; $p<0.001$ ), itching (38.55\% improvement; $p<0.001$ ), swelling (44\% improvement; $p<0.001$ ), bleeding (17.28\% improvement; $p<0.007$ ), discomfort $(34.01 \%$ improvement; $p<0.001)$, and wellbeing $(32.35 \%$ improvement; $p<0.001$ ), giving an average overall opinion on the therapy of $4 / 10$.
\end{abstract}

received

August 15, 2020

accepted

January 15, 2021

published online

June 3, 2021
DOI https://doi.org/

$10.1055 / \mathrm{s}-0041-1730012$. ISSN 2237-9363.

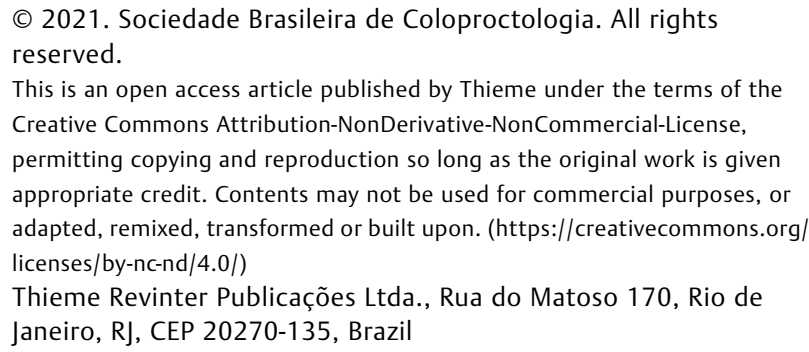

This is an open access article published by Thieme under the terms of the Creative Commons Attribution-NonDerivative-NonCommercial-License, permitting copying and reproduction so long as the original work is given appropriate credit. Contents may not be used for commercial purposes, or adapted, remixed, transformed or built upon. (https://creativecommons.org/ licenses/by-nc-nd/4.0/)

Thieme Revinter Publicações Ltda., Rua do Matoso 170, Rio de Janeiro, RJ, CEP 20270-135, Brazil 


\section{Resumo}

\author{
Palavras-chave \\ - hemorroidas \\ - hirudoterapia \\ - medicina Unani \\ - bawaseer \\ - irsal-e-alaq
}

Conclusion The results of the study albeit smaller in sample size show that MLT is an effective and safe therapeutic option in reducing the symptoms of $3^{\text {rd }}$ and $4^{\text {th }}$ degree haemorrhoids.

Objetivos As hemorroidas são caracterizadas por sangramento, secreção mucosa, prurido, dor e prolapso. Esta condição é conhecida como bawaseer na medicina Unani, e a Hirudinaria granulosa tem sido usada para seu tratamento na Irsal-e Alaq, ou hirudoterapia, há séculos. A $\mathrm{H}$. granulosa, devido à sua ação antitrombótica e antiinflamatória, é utilizada no tratamento de doenças venosas crônicas e hemorroidas. $\mathrm{O}$ presente estudo teve como objetivo investigar a eficácia da hirudoterapia em hemorroidas de terceiro e quarto graus.

Métodos Este ensaio clínico prospectivo e unicêntrico com delineamento pré e pósanálise foi conduzido no hospital do National Institute of Unani Medicine. Foram incluídos no estudo 20 pacientes de ambos os sexos, com média de idade de 38 anos, que apresentavam sintomas moderados avaliados pelo questionário colorectal evaluation of clinical therapeutics scale (CORECTS). Espécimes de $\mathrm{H}$. granulosa foram aplicadas em volta da área afetada por um período de 15 minutos semanais, durante 4 semanas. A eficácia do tratamento foi medida por uma avaliação objetiva e subjetiva usando o questionário CORECTS.

Resultados Quando analisada pelo clínico, a hirudoterapia reduziu o escore de gravidade dos sintomas nos seguintes domínios: dor (55\% de melhora; $p<0,001$ ); prurido anorretal (melhora de $30 \% ; \mathrm{p}<0,10$ ); e sangramento (melhora de $10 \%$; $p<0,7963)$. Melhora significativa $(p<0,001)$ foi relatada no escore CORECTS em relação à dor (44,09\% de melhora; $p<0,001)$, prurido (38,55\% de melhora; $p<0,001)$, inchaço ( $44 \%$ de melhora; $p<0,001)$, sangramento $(17,28 \%$ de melhora; $p<0,007)$, desconforto $(34,01 \%$ de melhora; $p<0,001)$ e bem-estar $(32,35 \%$ de melhora; $\mathrm{p}<0,001$ ), o que resultou em uma opinião geral média sobre a terapia de $4 / 10$.

Conclusão Os resultados do estudo, embora com tamanho de amostra pequeno, mostram que a hirudoterapia é uma opção terapêutica eficaz e segura na redução dos sintomas de hemorroidas de terceiro e quarto graus.

\section{Introduction}

Hemorrhoidal disease is one of the most common anorectal conditions encountered in daily practice in India. It has been projected that about $50 \%$ of the population will have hemorrhoids at some point in their life. ${ }^{1}$ Hemorrhoids are dilated plexus of the superior hemorrhoidal veins, in relation to the anal canal. ${ }^{2}$ They represent abnormal enlargement of the anal cushions. ${ }^{3}$ Clinically characterized by bleeding from the rectum, mucous discharge, perianal irritation or pruritus, perianal pain, prolapse of the hemorrhoidal cushions, or protruding mass, soiling, and difficulties with hygiene. The exact prevalence of symptomatic hemorrhoids is difficult to establish owing to under-reporting by patients. ${ }^{4}$ In the United States, it is the fourth leading outpatient gastrointestinal diagnosis, accounting for 3.3 million ambulatory care visits. Despite its prevalence and low morbidity, hemorrhoid disease has a high impact on the quality of life. ${ }^{5}$

The exact pathophysiology of symptomatic hemorrhoid disease is poorly understood. Previous theories that described hemorrhoids as anorectal varices are now obsolete. However, a variety of possible contributing factors leading to migration of the hemorrhoidal cushions has been suggested, including lack of dietary fiber, chronic straining, spending excess time on the commode, constipation, diarrhea, pregnancy, sedentary lifestyle, and a family history. ${ }^{6}$

Currently, the theory of sliding anal canal lining, which proposes that hemorrhoids occur when the supporting tissues of the anal cushions deteriorate, is more widely accepted. Advancing age and activities such as strenuous lifting, straining with defecation, and prolonged sitting are thought to contribute to this process. Hemorrhoids are, therefore, the pathological term to describe the abnormal downward displacement of the anal cushions causing venous dilatation. ${ }^{5}$

Hemorrhoids are classified into internal and external . Internal hemorrhoids are divided into four degrees, First degree; the hemorrhoid does not come out of the anus, second degree: the hemorrhoid comes out only during defecation but is spontaneously reduced, third degree: the 
hemorrhoid needs to be manually replaced, and fourth degree: the hemorrhoid is permanently prolapsed. ${ }^{2}$

The treatment options for hemorrhoidal disease range from conservative management with advice on diet, lifestyle changes, and application of topical ointments to interventions that can be performed on an outpatient setting (such as rubber band ligation, infrared coagulation, and injection sclerotherapy) as well as surgical treatments. Based on the degree of prolapse and the classification by Banov and colleagues, $3^{\text {rd }}$ and $4^{\text {th }}$ degree hemorrhoids are amenable to surgical treatment. ${ }^{5}$

The surgical treatment for hemorrhoids has pros and cons; two commonly used excision procedures worldwide are the Milligan-Morgan (open) and the Ferguson (closed) hemorrhoidectomies. Postoperative pain and complications (urinary retention, wound complications, recurrent bleeding, constipation, and anal fissure) are believed to be the most important disadvantages of this techniques. ${ }^{4}$ The postoperative complications and chance of recurrence in the conventional treatment of third and fourth-degree internal hemorrhoids (prolapsed hemorrhoids requiring manual reduction and non-reducible prolapsed hemorrhoids respectively) are the major draw backs that warrant seeking alternative therapies.

Unani Medicine is one of the oldest traditional medicines established on the Hippocratic doctrine of the four humors theory, practiced widely in the Indian subcontinents. Hemorrhoid in Unani medicine is described as Bawaseer which develops due to abnormal viscosity and quantity of khilte sawda (melancholic humor) in blood and it is managed through diet and lifestyle changes, pharmacotherapy as well as regimental therapies. Various regimenal therapies especially venesection, wet cupping and leech therapy are used to evacuate the abnormal blood. In Unani medicine, medicinal leech therapy (MLT) is known as irsal-e-alaq, and it is an important and effective method of bloodletting which is used in the treatment of hemorrhoids. ${ }^{7}$ Hirudinaria granulosa is a type of leech commonly used for medicinal purposes in India. ${ }^{8}$ The efficacy of MLT has been investigated in several studies, and it is found to be highly effective in reducing the symptoms of hemorrhoids. ${ }^{9-11}$

The probable mode of action of MLT is dependent on two factors: amount of blood removed by suction of leech which is approximately 5 to $15 \mathrm{ml}$ and on an average 50 to $150 \mathrm{ml}$ of blood that oozes up to 10 to $48 \mathrm{~h}$ post MLT session. The second factor is therapeutic action of Leech Saliva that is poured in host body. The leach saliva contains several bioactive components that attributes to its therapeutic uses in wide range of disease. ${ }^{12,13}$ In this study the efficacy of MLT was investigated as a novel and curative mode of treatment in reducing symptoms of third and fourth-degree hemorrhoids.

\section{Methods}

This is an open labelled non-randomized, single-arm study with pre and postanalysis was conducted between March 2015 and December 2015 at the hospital of the National Institute of Unani Medicine, which is affiliated with the Rajiv Gandhi University of Health Sciences, Bengaluru, India. The protocol was approved by the Institutional Ethics Committee (IEC No:NIUM / IEC /2013-14 / Moal / 04 Dated:24.04.2014) and registered in the Indian registry of clinical trial with the number-CTRI/2018/03/012326. The sample size was estimated by assuming $\alpha=0.05$ and $\beta=$ 0.2 . The known population mean and standard deviation $(S D)=3.05 \pm 0.73$ were taken from a previous study, ${ }^{11}$ and the anticipated mean in the study group was 3.51 . The sample size was calculated as 20 patients. Patients clinically diagnosed with third and fourth degree hemorrhoids were enrolled after signing a written informed consent. A total of 23 patients fulfilled the clinical inclusion criteria and were treated with MLT and followed-up weekly during the treatment, which lasted 4 weeks.

\section{Inclusion and Exclusion Criteria}

Patients diagnosed with third and fourth-degree hemorrhoids, with ages between 20 and 60 years, of either gender who were willing to participate in the study by signing the consent form and committing to follow the protocol were included. Patients younger than 20 or older than 60 years of age as well as those with blood/coagulation disorders, hypertension, diabetes mellitus, severe systemic illness, pregnant and lactating women, or secondary hemorrhoids were excluded.

\section{Study Outcome Measures}

The assessment of the efficacy of the treatment was carried out based on the main outcome measure of the Colorectal Evaluation of Clinical Therapeutics Scale (CORECTS), ${ }^{14}$ which consists the five chief symptoms of hemorrhoids, that is, pain, itching, swelling, bleeding, and discomfort. Each symptom is rated on a numeric scale from $0=$ no symptoms to $10=$ worst possible symptoms. In addition, the CORECTS also accounts for quality of life, with an impact on wellbeing (IW) score ranging from 0 (no impact) to 10 (worst possible impact on wellbeing). Overall improvement after treatment ranges from $0=$ no improvement at all to $10=$ maximal improvement comparable to the healthy state. The efficacy assessment was carried out by comparing the baseline with the posttreatment data.

\section{Trial Regimen (Medicinal Leech Therapy)}

Medicinal leeches identified as Hirudinaria granulosa were supplied by a local breeder and suppliers of laboratory animals, Sri Raghuvendra Enterprises, Marenhalli, Vijayanagara, Bengaluru, India. The leeches were stored in the regimental therapy unit in their ideal habitat. Two to three leeches (as per requirement) were applied weekly (on day 0 , and then on the $7 \mathrm{th}, 14^{\text {th }}$, and $21^{\text {st }}$ days). The leeches were bathed in turmeric water for detoxification and cleaned with a sponge. Before the application of the leeches, all the necessary investigations, such as bleeding time, clotting time, platelet count, and random blood sugar, have been carried out for exclusion. All the necessary aseptic measures were adopted, such as vaccinating patients for tetanus toxoid (TT) and cleaning the application site with antiseptic lotion and drying it before the application of leeches over the pile 
mass. The leeches sucked the blood on the hemorrhoidal mass for approximately 15 minutes and usually detached themselves thereafter or were separated by dusting turmeric powder on their mouths. After the detachment, the bite area was deliberately left open for a few minutes for after-bite blood oozing and dressed thereafter with sterile pad and antiseptic lotion. The patient was advised to avoid any strenuous physical activity and to not defecate for a few hours after the procedure. The anal area was routinely observed for any swelling or infection. Later, the used leeches were washed in fresh water and stored in labelled bottles containing fresh water to be reused in the same patient on the follow-up session. The duration of the present study was 4 weeks, and the patients were clinically assessed and followed-up weekly on day 0 , and then on the $7^{\text {th }}, 14^{\text {th }}$, $21^{\text {st }}$, and $28^{\text {th }}$ days for outcomes and possible adverse effects.

\section{Statistical Analysis}

As shown in - Fig.1, a total of 64 patients with third and fourth-degree hemorrhoids visiting the NIUM hospital were assessed for enrolment in the present study. Only 23 patients met the inclusion criteria and agreed to participate in the study. Among these 23 patients, 3 were excluded, and, finally, 20 patients completed the study.

A descriptive and inferential statistical analysis was carried out with statistical software, namely SAS 9.2 (SAS, Inc., Cary, NC, USA), SPSS Statistics for Windows, Version 15.0 (SPSS Inc., Chicago, IL, USA), Stata 10.1 (Stata Corp, LLC, College Station, TX, USA), MedCalc 9.0.1, Systat 12.0 (Systat Inc., Chicago, IL, USA) and $\mathrm{R}$ environment ver. 2.11.1. The descriptive data are represented by mean and SD. The Student $t$-test (two tailed, depen- dent) was used to find the significance of the mean difference between the pre and posttreatment values of the study parameters. A $p$-value 0.05 was considered statistically significant.

\section{Results}

The baseline characteristic of the patients enrolled is shown in -Table 1. Out of 20 patients, there were 2 female and 18 male with a mean age of 38 years. At the baseline of the study, all patients had moderate symptoms when evaluated with the CORECTS, ${ }^{14}$ as shown in - Table 2. Investigations, other than routine baseline tests, were performed as needed. None of the patients had anemia or bleeding disorders.

When analyzed by the clinician, MLT reduced the symptoms severity score, such as pain (55\% improvement; $p<0.001$ ), which was significant; and anorectal itching (30\% improvement; $p<0.10$ ), and bleeding (10\% improvement; $p<0.7963$ ), which were not statistically significant. The severity of third and fourth-degree hemorrhoids was assessed by using the CORECTS questionnaire at baseline and on the $28^{\text {th }}$ day, and the results are summarized in - Table 2 . There was statistically significant reduction in the symptoms score $(p<0.001)$ from baseline to the 28th day, which was determined by using the Student $t$-test (paired). Pain was reduced from $6.35 \pm 1.50$ to $3.55 \pm 1.79$ (44.09\% improvement; $p<0.001)$; the itching score was reduced from $4.15 \pm 1.66$ to $2.55 \pm 1.36(38.55 \%<0.001)$; the swelling score was reduced from $7.50 \pm 1.40$ to $4.20 \pm 1.06$ $(44 \%<0.001)$; the bleeding score $(17.28 \% 0.007)$ and discomfort was $7.35 \pm 1.04$ and $4.80 \pm 1.15(34.01 \%<0.001)$. The impact on the well-being score was reduced from

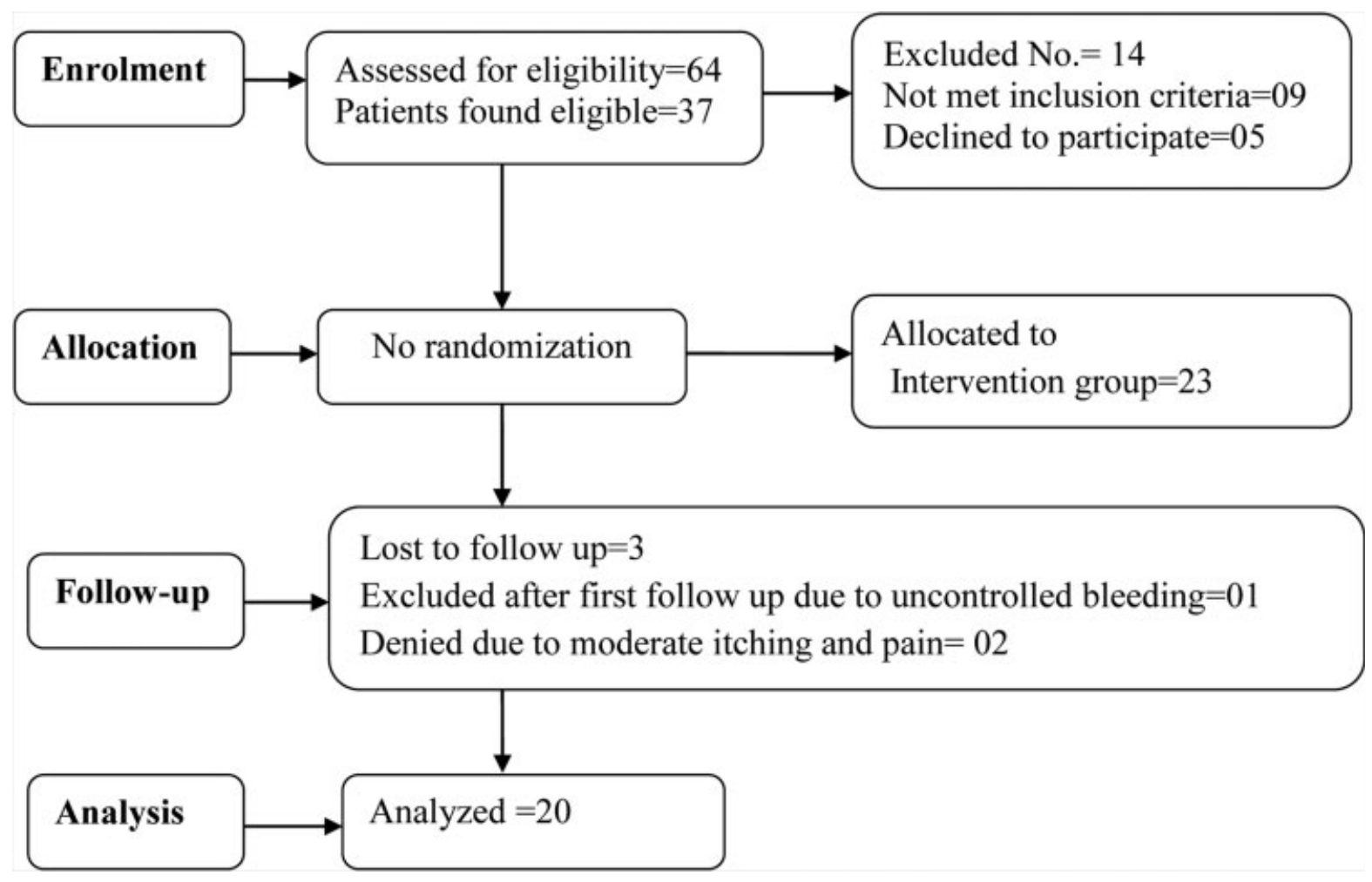

Fig. 1 COSORT flow chart of the patients studied. 
Table 1 Demography and characteristic detail of patients at baseline

\begin{tabular}{|l|l|l|l|}
\hline \multicolumn{2}{|l|}{ Age in years (mean \pm SD) } & $38.35 \pm 11.32$ & $\%$ \\
\hline Gender & Female/Male & $02 / 18$ & $10 / 90$ \\
\hline Religion & Hindu/Muslim & $04 / 16$ & $20 / 80$ \\
\hline Marital status & $\begin{array}{l}\text { Married/ } \\
\text { Unmarried }\end{array}$ & $18 / 02$ & $90 / 10$ \\
\hline Diet & $\begin{array}{l}\text { Mixed diet/ } \\
\text { Vegetarians }\end{array}$ & $19 / 01$ & $95 / 05$ \\
\hline
\end{tabular}

$6.80 \pm 1.01$ to $4.60 \pm 0.99(32.35 \%<0.001)$ at baseline and on the 28th day of treatment, respectively, which was significant. The overall improvement mean score of the responses was $3.75 \pm 1.37$ (range 0 -10), with a median response of 4 . The result shows that MLT effectively reduced the symptoms of pain, itching, swelling, bleeding, and discomfort in third and fourth-degree hemorrhoid patients as well as improved their quality of life $(p<0.001)$ - Table 2 .

The patients were assessed clinically for adverse effects and possible complications of MLT, such as itching, bleeding, vasovagal symptoms, and regional lymphadenopathy. Out of 23 enrolled patients, only 1 presented bleeding, which was managed but excluding the patient. Two patients complained of moderate itching and pain; later, they refused to continue the treatment and, therefore, were excluded from the study. As shown in - Table 3, safety was evaluated on hematological and biochemical parameters at baseline and on the $28^{\text {th }}$ day, and all parameters were found to be within normal range.

\section{Discussion}

Irsal-e-Alaq, or MLT, is a treatment regimen that has been used to treat patients for centuries. It has been known for a long time, more than 2,500 years, and it is still alive. ${ }^{15}$ The earliest clearly documented record of leeches being used for medicinal purposes surfaced in a painting in an Egyptian tomb of around $1500 \mathrm{BC} .{ }^{16}$ In Unani medicine, Irsal-e- Alaq, or MLT, is used to remove "morbid humors", especially blood, from a particular body part in an attempt to balance the "biological humors". It is mentioned in classical literature by Zakariya Razi, Ali Ibn Abbas Majoosi, Abul Qasim Zahrawi, and Avicenna in their text books. ${ }^{17-20}$
Table 3 Means and standard deviation of the safety measures

\begin{tabular}{|l|l|l|l|}
\hline Investigations & BT & AT & $P$-value \\
\hline $\mathrm{BU}(\mathrm{mg} / \mathrm{dl})$ & $26.50 \pm 5.79$ & $28.75 \pm 5.90$ & 0.312 \\
\hline $\mathrm{SC}(\mathrm{mg} / \mathrm{dl})$ & $0.79 \pm 0.23$ & $0.83 \pm 0.21$ & 0.634 \\
\hline SGPT $(\mathrm{IU} / \mathrm{L})$ & $23.65 \pm 7.65$ & $26.40 \pm 17.46$ & 0.444 \\
\hline SGOT $(\mathrm{IU} / \mathrm{L})$ & $21.70 \pm 8.08$ & $21.05 \pm 5.77$ & 0.668 \\
\hline
\end{tabular}

Abbreviations: AT, after treatment; BT, before treatment; BU, blood urea; SC, serum creatinine; SGOT, serum glutamic oxaloacetic transaminase; SGPT, serum glutamic pyruvic transaminase.

In conventional medicine, MLT is a multi-faceted therapeutic concept, and it has been proven to be an effective treatment regimen for a number of disorders, including skin, and musculoskeletal disorders and wounds. It comprises the biting stimulus and blood drawing by leeches and injection of their saliva into the patients' blood and tissues. The mechanism of action of MLT depends upon a complex mixture of different biological and pharmacologically-active substances secreted from the salivary glands of the leech into living organisms while feeding on them. ${ }^{21}$ Its therapeutic effects include antiinflammatory, analgesic, and bacteriostatic actions, anti-coagulant, and blood and lymph flow stimulation. ${ }^{22}$ The most common bioactive substance is hirudin, which prevents the process of blood clotting. 22

Contrary to popular traditional belief, leeches commonly absorb about $5 \mathrm{ml}$ of blood; however, if more leeches are applied to the affected site, their impact is enhanced. The mode of action of MLT depends on the injection of other biologically active substances with the saliva into the host tissue and blood, in which approximately 5 to $15 \mathrm{ml}$ of blood is removed by the suction action of leech therapy, ${ }^{12}$ followed by passive oozing of approximately 50 to $150 \mathrm{ml}$ of blood up to 10 to 48 hours after removal of leeches. The blood oozes due to the action of the hirudin in the leeches' saliva injected into wound site, and it remains active for several hours after removal of the leeches. ${ }^{12}$ Injection of other biologically active substances with the saliva into the host tissue and blood. The saliva contains more than 100 bioactive substances, including coagulation inhibitors, platelet aggregation inhibitors, vasodilators, and anaesthetizing, antimicrobial and antiinflammatory agents. ${ }^{13}$

Table 2 Means and standard deviation of the outcome measures when evaluated on CORECTS at baseline and on the $28^{\text {th }}$ day

\begin{tabular}{|l|l|l|l|l|l|}
\hline CORECT Scale & BT & AT & Difference & Decrease (\%) & $P$-value \\
\hline Pain & $6.35 \pm 1.50$ & $3.55 \pm 1.79$ & 2.800 & 44.09 & $<0.001^{* *}$ \\
\hline Itching & $4.15 \pm 1.66$ & $2.55 \pm 1.36$ & 1.600 & 38.55 & $<0.001^{* *}$ \\
\hline Swelling & $7.50 \pm 1.40$ & $4.20 \pm 1.06$ & 3.300 & 44 & 17.28 \\
\hline Bleeding & $4.05 \pm 2.58$ & $3.35 \pm 2.54$ & 0.700 & 34.01 & $<0.001^{* *}$ \\
\hline Discomfort & $7.35 \pm 1.04$ & $4.80 \pm 1.15$ & 2.550 & 32.35 & $<0.007^{* *}$ \\
\hline Impact on wellbeing & $6.80 \pm 1.01$ & $4.60 \pm 0.99$ & 2.200 & & $<0.001^{* *}$ \\
\hline
\end{tabular}

Abbreviations: AT, after treatment; BT, before treatment.

** Statistically significant change was noted $(p<0.001)$ using the Student $t$-test (paired).

J Coloproctol Vol. 41 No. 2/2021 $\quad$ @ 2021. Sociedade Brasileira de Coloproctologia. All rights reserved. 
This study, to the best of our knowledge, is the first of its kind to describe the use of MLT in the treatment of third and fourth-degree internal hemorrhoids. The results showed that MLT significantly reduced the severity of symptoms of third and fourth-degree internal hemorrhoids and improved the quality of life, as shown in - Table 2. The significant changes in the present study were supported by the findings of previous studies on MLT for the treatment of hemorrhoids. ${ }^{9-11,23,24}$

In the present study, significant decrease $(p<0.001)$ in pain and swelling was noted. The bioactive components of leech saliva (hirustastin, ghilantens, eglin C, bdelins') act as antiinflammatory and analgesic agents to help reduce the swelling and pain. ${ }^{12}$ Apart from the antiinflammatory components, leeches' saliva also has an anesthetic constituent that reduces pain and provides symptomatic relief. $8,23,25$ Some other hypotheses postulate reduction of pain through the antinociceptive effects of leeches' saliva and hirudin, which can inhibit platelet-derived growth factor (PDGF), a factor involved in pain induction. ${ }^{26}$ The bioactive substances in leeches' saliva, which include hirudin (thrombin inhibitor), histamine-like vasodilator, kallikrein, tryptase and other proteinase inhibitors, and hyaluronidase, have pharmacological properties that, together, may contribute to analgesia. ${ }^{26}$ Contrary to the idea of the pharmacological action of the bioactive substances in leeches' saliva, some authors suggest that analgesia may be due to the fact that when the leeches suck the patient's blood, the interstitial fluid and passive oozing occurring from the pile mass reduces the edema to a great extent, which will, in turn, reduce the pain. ${ }^{11}$ The same statement has been given by Zakarya Razi in his book Al Hawi, in which he mentions that the pain caused by retention of hemorrhoidal blood is relieved by the initiation of bleeding. ${ }^{27}$

A significant decrease $(p<0.001)$ in itching and discomfort was also noted. Mucus discharge due to engorged mucous membrane excoriates the skin at the anus, leading to itching. Most often, itching is secondary to other causes, such as infection. ${ }^{28}$ The possible mechanism behind a decrease in symptoms of itching and discomfort may be explained by the antimicrobial activity of destabilase, chloromycetin, theromycin, theromyzin, and the anticoagulant action of the hirudin protein, gelin, eglins $\mathrm{C}$, and factor Xa inhibitor. $^{12}$ The cumulative actions of all these factors may increase the blood flow to the feeding, which results in reduced congestion of the mucous membrane and improvement in the symptoms of itching and discomfort.

A statistically significant change $(p<0.001)$ was also observed in the symptoms of bleeding. Bdellin A, which is present in leeches' saliva, acts as a plasmin inhibitor to control bleeding. $^{12}$ Other bioactive substances present in leeches' saliva can eliminate microcirculation disorders, restore permeability of tissue and organs, and reduce hypoxia and edema. ${ }^{29}$ The impact on wellbeing score was reduced from baseline to the 28th day was statistically significant $(p<0.001)$; thereby, the quality of life of the patients was improved markedly by enhancing their wellbeing. This significant reduction in symptom severity score contributed towards improving quality of life and decreasing the impact on wellbeing. The overall improvement score was noted at the end of the treatment by asking the patients a single question regarding their overall improvement with treatment. The mean score of the responses was $3.75 \pm 1.37$ (range $0-10$ ), with a median response of 4 . Medicinal leech therapy in the anorectal region makes the patients uncomfortable, as they have to expose their private parts, and it may be the reason the overall improvement score at the end of the treatment was not up to mark.

CORECTS was initially used for hemorrhoids specifically in pregnant condition in women. However it can be used to asses hemorrhoids in conditions other than pregnancy; however, the investigators found it a reliable tool in assessing the disease severity, and it was highly sensitive in detecting changes in symptom severity following treatment, which makes it a valuable tool for clinicians. ${ }^{14}$

According to Unani medicine, the pathology develops when the liver diverts putrid and viscous "melancholic blood" gradually towards the anal vessels; subsequently, a large amount of viscid blood accumulates in the anal area, ${ }^{27}$ consequently, extra growth/flesh develops on the veins of the anus due to excessive viscous "melancholic blood". 7,17 The emphasis on elimination of the excess of "melancholic blood" from the anal area remains the key in the management of hemorrhoids. Medicinal leech therapy is one of the most important and widely practiced methods used for local evacuation of "melancholic blood" in Unani medicine. The findings in this study support the conceptually based regimental therapy (MLT) of third and fourth-degree internal hemorrhoid.

In view of above facts and findings, MLT has proved to be a reliable treatment modality to reduce the symptoms of third and fourth-degree internal hemorrhoids and improve the quality of life. However, optimal care should be taken when applying leeches because their unsafe use can be associated with serious complications, rarely. The limitations of this study were that there was no randomization or control group; its small sample size as well as short duration of therapy and posttreatment follow-up. Hence, controlled clinical trials with larger sample size and posttreatment follow-up are required to further prove the efficacy and safety of this treatment regimen.

\section{Conclusion}

The present study shows that MLT relieves symptoms of third and fourth-degree hemorrhoids and improves the patient's quality of life. In light of our clinical findings, we believe that MLT has the potential of being an additional or alternative therapy to the non-surgical management of third and fourthdegree hemorrhoids. The clinical efficacy of MLT for the treatment of hemorrhoids should be further evaluated by conducting randomized controlled trials with a larger sample size.

\section{Highlights}

- Hemorrhoids are described in Unani medicine as Bawaseer, and this condition has been treated for centuries. 
- According to Unani Medicine, this disease arises due to an abnormal quality and quantity of humor, that is, dominance of Ghair Tabayi Khilte Sawda (abnormal melancholic humour), in the blood and anal region.

- Renowned scholars and physicians of Unani medicine, like Hippocrates, Galen, Rhazes, and Avicenna, also treated such ailment through Unani medicine (plant, mineral and animal-origin drugs, like leech therapy).

- The treatment of hemorrhoids with MLT is one of the regimens described and practiced for manifestations of blood disorders in Unani medicine, and it may lead to a better management of the hemorrhoids.

\section{Disclaimer}

The present paper presents the findings of the postgraduate research dissertation submitted to Rajiv Gandhi University of Health Sciences, Karnataka

\section{Conflict of Interests}

The authors declare that there is no conflict of interests.

\section{Acknowledgement}

The present study has been financially supported by the National Institute of Unani Medicine, Bengaluru, (affiliated with the Rajiv Gandhi University of Health Sciences, Karnataka) Ministry of AYUSH, Govt. of India. We are thankful to the Director for sponsoring this study. The authors would like to thank Dr K. P. Suresh, from the Department of Biostatistics, of the National Institute of Animal Nutrition and Physiology, Bangalore, India, for the statistical evaluation and data analysis.

\section{References}

1 Agarwal N, Singh K, Sheikh P, Mittal K, Mathai V, Kumar A. Executive Summary - The Association of Colon \& Rectal Surgeons of India (ACRSI) Practice Guidelines for the Management of Haemorrhoids-2016. Indian J Surg 2017;79(01):58-61. Doi: 10.1007/s12262-016-1578-7

2 Shenoy KR, Nileshwar A. Manipal Manual of Surgery. 3rd ed. New Delhi: CBS Publishers \& Distributors Pvt Ltd; 2010: 643-647

3 Standring S. Gray's Anatomy The Anatomical Basis of Clinical Practice. 39th ed.Edinburgh: Elsevier Ltd; 2005:1205-1210

4 Simillis C, Thoukididou SN, Slesser AA, Rasheed S, Tan E, Tekkis PP. Systematic review and network meta-analysis comparing clinical outcomes and effectiveness of surgical treatments for haemorrhoids. Br J Surg 2015;102(13):1603-1618. Doi: 10.1002/bjs.9913

5 Sun Z, Migaly J. Review of hemorrhoid disease: presentation and management. Clin Colon Rectal Surg 2016;29(01):22-29http:// dx.doi.org/10.1055/s-0035-1568144

6 Ganz RA. The evaluation and treatment of hemorrhoids: a guide for the gastroenterologist. Clin Gastroenterol Hepatol 2013;11 (06):593-603. Doi: 10.1016/j.cgh.2012.12.020

7 Khan MA. Akseer-e Aazam (Urdu Translation). New Dehli: Idara Kitab Us Shifa; 2011:661-673
8 Zaidi SM, Jameel SS, Zaman F, Jilani S, Sultana A, Khan SA. A systematic overview of the medicinal importance of sanguivorous leeches. Altern Med Rev 2011;16(01):59-65

9 Bhagat PJ, Raut SY, Lakhapati AM. Clinical efficacy of Jalaukawacharana (leech application) in Thrombosed piles. Ayu 2012;33 (02):261-263. Doi: 10.4103/0974-8520.105248

10 Najar FA, Khan JA, Fatima M, Ahmad K, Fasial M. Efficacy of Taleeq (Leech Therapy) in the Management of Bawaseer (Haemorrhoid): A Case Series. Research \&Reviews. A Journal of Unani. Siddha and Homeopathy 2016;3(01):5-8

11 Ravishankar AG, Rao R, Mahesh TS, Subrahmanya P, Krishnamurthy MS. Leech on External Thrombosed Hemorrhoids. Int Res J Pharm 2013;4(11):50-52

12 Singh SK, Rajoria K. Medical leech therapy in Ayurveda and biomedicine - A review. J Ayurveda Integr Med 2020;11(04): 554-564

13 Asutkar S, Varshney S. An Interdisciplinary Critical Review of Leech Therapy; Evolution, Indications, Salivary Gland Secretions and Mode of Action- The Scientific Way. J Pharm (IOSRPHR) 2019; 9(04):10-18

14 Ebrahimi N, Vohra-Miller S, Koren G. Anorectal symptom management in pregnancy: development of a severity scale. J Popul Ther Clin Pharmacol 2011;18(01):e99-e105

15 Ahmad T, Anwar M. Clinical Importance of Leech Therapy. Indian Tradit Know 2009;8(03):443-445http://nopr.niscair.res.in/handle/ $123456789 / 5069$

16 Munshi Y, Ara I, Rafique H, Ahmad Z. Leeching in the history-a review. Pak J Biol Sci 2008;11(13):1650-1653

17 Majusi AIA. Kamilus Sana'a (Urdu Translation). Vol. II part II. New Delhi: CCRUM; 2010:268

18 Razi AMBZ. Kitabul Mansoori Urdu Translation. 1st ed. New Delhi: CCRUM; 1991;284:382-384, 254

19 Al Zahrawi AQ. Jarahiyat-I Zahrawi Urdu Translation. New Delhi: CCRUM; 2012:23-24, 140, 187

20 Kabeeruddeen M. Tarjuma wa Sharah Kulliyat-e Qanoon Urdu Translation. New Delhi: Aijaz Publishing House; 2006:350-352

21 Singh AP. Medicinal leech therapy (hirudotherapy): a brief overview. Complement Ther Clin Pract 2010;16(04):213-215. Doi: 10.1016/j.ctcp.2009.11.005

22 Koeppen D, Aurich M, Pasalar M, Rampp T. Medicinal leech therapy in venous congestion and various ulcer forms: Perspectives of Western, Persian and Indian medicine. J Tradit Complement Med 2019;10(02):104-109. Doi: 10.1016/j.jtcme.2019.08.003

23 Sarika S, Kedar NitaM, Raut SubhashY, Lakhpati ArunM. Role of Jalaukavacharan in Thrombosed Hemorrhoids, A Case Study. Int. J. Ayur. Pharma Research 2014;2(03):100-3

24 Gupta RMeenakshi. Leech Therapy in Thrombosed Piles. International Ayurvedic Medical Journal 2015;3(04):1273-1276

25 Abdullah S, Dar LM, Rashid A, Tewari A. Hirudotherapy /Leech therapy: Applications and Indications in Surgery. Arch Clin Exp Surg 2012;1(03):172-180

26 Gunawan F, Wibowo YR, Bunawan NC, Turner JH. Controversy: hirudotherapy (leech therapy) as an alternative treatment for osteoarthritis. Acta Med Indones 2015;47(02):176-180

27 Razi AMBZ. Kitabul Havi (Urdu Translation). Vol. 11. New Dehli: CCRUM; 2004:27-68

28 Khubchandani I, Paonessa N, Azimuddin K. Surgical Treatment of Hemorrhoids. 2nd ed. London: Springer; 2009

29 Ingole AR, Dhabarde DM, Kamble MA, Potnis VV. Modern Touch to Traditional Leech Therapy: A Review. Res J Pharm Biol Chem Sci 2013;4(03):557-563 